\title{
The first aerosol indirect effect quantified through airborne remote sensing during VOCALS-REx
}

\author{
D. Painemal ${ }^{1}$ and P. Zuidema ${ }^{2}$ \\ ${ }^{1}$ NASA Langley Research Center, Hampton, VA, USA \\ ${ }^{2}$ Rosenstiel School of Marine and Atmospheric Sciences, University of Miami, Key Biscayne, Fl, USA
}

Correspondence to: D. Painemal (david.painemal@nasa.gov)

Received: 5 September 2012 - Published in Atmos. Chem. Phys. Discuss.: 25 September 2012

Revised: 5 January 2013 - Accepted: 7 January 2013 - Published: 22 January 2013

\begin{abstract}
The first aerosol indirect effect (1AIE) is investigated using a combination of in situ and remotelysensed aircraft (NCAR C-130) observations acquired during VOCALS-REx over the southeast Pacific stratocumulus cloud regime. Satellite analyses have previously identified a high albedo susceptibitility to changes in cloud microphysics and aerosols over this region. The 1AIE was broken down into the product of two independently-estimated terms: the cloud aerosol interaction metric $\mathrm{ACI}_{\tau}=\left.\frac{d \ln \tau}{d \ln N_{\mathrm{a}}}\right|_{\mathrm{LWP}}$, and the relative albedo (A) susceptibility $S_{R-\tau}=\left.\frac{d A}{3 d \ln \tau}\right|_{\text {LWP }}$, with $\tau$ and $N_{\mathrm{a}}$ denoting retrieved cloud optical thickness and in situ aerosol concentration respectively and calculated for fixed intervals of liquid water path (LWP).

$\mathrm{ACI}_{\tau}$ was estimated by combining in situ $N_{\mathrm{a}}$ sampled below the cloud, with $\tau$ and LWP derived from, respectively, simultaneous upward-looking broadband irradiance and narrow field-of-view millimeter-wave radiometer measurements, collected at $1 \mathrm{~Hz}$ during four eight-hour daytime flights by the C-130 aircraft. ACI $\tau$ values were typically large, close to the physical upper limit (0.33), with a modest increase with LWP. The high ACI $\tau$ values slightly exceed values reported from many previous in situ airborne studies in pristine marine stratocumulus and reflect the imposition of a LWP constraint and simultaneity of aerosol and cloud measurements. $S_{R-\tau}$ increased with LWP and $\tau$, reached a maximum $S_{R-\tau}(0.086)$ for LWP $(\tau)$ of $58 \mathrm{~g} \mathrm{~m}^{-2}$ $(\sim 14)$, and decreased slightly thereafter. The 1AIE thus increased with LWP and is comparable to a radiative forcing of $-3.2--3.8 \mathrm{~W} \mathrm{~m}^{-2}$ for a $10 \%$ increase in $N_{\mathrm{a}}$, exceeding previously-reported global-range values. The aircraftderived values are consistent with satellite estimates derived from instantaneous, collocated Clouds and the Earth's Radi-
\end{abstract}

ant Energy System (CERES) albedo and MOderate resolution Imaging Spectroradiometer (MODIS)-retrieved droplet number concentrations at $50 \mathrm{~km}$ resolution. The consistency of the airborne and satellite estimates, despite their independent approaches, differences in observational scales, and retrieval assumptions, is hypothesized to reflect the ideal remote sensing conditions for these homogeneous clouds. We recommend the southeast Pacific for regional model assessments of the first aerosol indirect effect on this basis. This airborne remotely-sensed approach towards quantifying 1AIE should in theory be more robust than in situ calculations because of increased sampling. However, although the technique does not explicitly depend on a remotelyderived cloud droplet number concentration $\left(N_{\mathrm{d}}\right)$, the attimes unrealistically-high $N_{\mathrm{d}}$ values suggest more emphasis on accurate airborne radiometric measurements is needed to refine this approach.

\section{Introduction}

The First Aerosol Indirect Effect (1AIE) is the cloud albedo enhancement that results from an increase in the cloud droplet number concentration and optical thickness due to increases in the aerosol burden with all other cloud properties, typically cloud liquid water path, held constant (Twomey, 1977). This effect has by now been widely observed. Largescale model comparisons with selected observations (e.g., Quaas et al., 2009) reveal a large spread among the different 1AIE estimates. This suggests that further observational estimates of the first AIE for specific well-characterized regions can be valuable for assessing model behavior more deeply. 
An adequate evaluation of $1 \mathrm{AIE}$ requires taking into account its two components, that is, the effect of the aerosols on the cloud microphysics (cloud-aerosol interactions), and the albedo perturbations that arise from the changes in the cloud properties. The aerosol-cloud interactions (ACI) component has typically been investigated with a simple metric proposed by Feingold et al. (2001):

$$
\mathrm{ACI}_{N}=\left.\frac{d \ln N_{\mathrm{d}}}{d \ln N_{\mathrm{a}}}\right|_{\mathrm{LWP}}
$$

$N_{\mathrm{a}}$ and $N_{\mathrm{d}}$ are the aerosol and the cloud droplet number concentration respectively. One approach for isolating the aerosol effect from dynamical influences is to calculate $\mathrm{ACI}_{N}$ for constrained values of the cloud liquid water path (LWP). Alternatively, the metric can be also expressed in terms of the cloud optical thickness $\tau$ or cloud effective radius $r_{\mathrm{e}}$ as:

$$
\mathrm{ACI}_{\tau}=\left.\frac{\partial \ln \tau}{\partial \ln N_{\mathrm{a}}}\right|_{\mathrm{LWP}} \quad \mathrm{ACI}_{r}=\left.\frac{\partial \ln r_{\mathrm{e}}}{\partial \ln N_{\mathrm{a}}}\right|_{\mathrm{LWP}}
$$

\section{(McComiskey and Feingold, 2008)}

When the cloud structure is well described by an adiabaticlike stratification of the water content, with a constant $N_{\mathrm{d}}$ with height, and $r_{\mathrm{e}}$ that linearly increases from the cloud base, the three different ACI can be related as:

$\mathrm{ACI}_{N}=3 \cdot \mathrm{ACI}_{\tau}=-3 \cdot \mathrm{ACI}_{r}$

The coefficient 3 in the equality (3) arises from the relationships $N_{\mathrm{d}} \propto \mathrm{LWP}^{1 / 2} r_{\mathrm{e}}^{-3}$ with LWP $\propto \tau \cdot r_{\mathrm{e}}$ (Bennartz, 2007). If one assumes that a fractional change in $N_{\mathrm{a}}$ cannot produce a larger fractional change in $N_{\mathrm{d}}$, then $\mathrm{ACI}_{N} \leq 1$. Thus, according to (3): $\mathrm{ACI}_{\tau}=-\mathrm{ACI}_{r} \leq 0.33$. In more complex environments like those found in heavily polluted continental areas, changes in cloud microphysics also depend on the shape of the aerosol size distributions, solubility and updrafts velocity, and the ACI metrics become less suitable estimators of the aerosol-cloud interactions. Nevertheless, these simple metrics should capture most of the aerosol influence in the cloud (Feingold, 2003), particularly for the relatively pristine marine air of the southeast Pacific. In this study, we adopted $\mathrm{ACI} \tau$ to investigate $1 \mathrm{AIE}$.

The component of $1 \mathrm{AIE}$ that links perturbations in the cloud microphysics with changes in albedo (A) can be expressed through the albedo susceptibility metric $(\mathrm{S})$, defined as:

$S=\left.\frac{d A}{d N_{\mathrm{d}}}\right|_{\mathrm{LWP}}$

(Platnick and Twomey 1994)
Or, in terms of fractional changes of $N_{\mathrm{d}}$, as the relative albedo susceptibility $\left(\mathrm{S}_{R}\right)$ :

$S_{R}=\left.\frac{d A}{d \ln N_{\mathrm{d}}}\right|_{\mathrm{LWP}}$

(Platnick and Oreopoulos, 2008)

Our analysis is kept independent of a remotely sensed value of $N_{\mathrm{d}}$ by expressing $S_{R}$ in terms of $\tau$, or, $S_{R-\tau}$. $S_{R-\tau}$ accounts for most of the $S_{R}$ magnitude (Platnick and Oreopoulos, 2008):

$S_{R-\tau}=\frac{1}{3} \frac{d A}{d \ln \tau}$

(Platnick and Oreopoulos, 2008)

We can finally quantitatively reconstruct the 1AIE by combining ACI and $S_{R}$ :

$1 \mathrm{AIE}=\left.\frac{d A}{d \ln N_{\mathrm{a}}}\right|_{\mathrm{LWP}}=\mathrm{ACI}_{N} \cdot S_{R}=3 \cdot \mathrm{ACI}_{\tau} \cdot S_{R-\tau}$

In this investigation, we assess the first aerosol indirect effect for Southeast Pacific (SEP) stratocumulus clouds. This marine region contains one of the most extended and persistent stratocumulus decks on the planet. Satellite analyses have revealed global-maximum values of the albedo susceptibility $\left(S_{R}\right)$ component of the 1AIE for the Southeast Pacific (e.g. Oreopoulos and Platnick, 2008; Painemal and Minnis, 2012), in part because a dry free troposphere does little to attenuate the top-of-cloud albedo (Zuidema et al., 2012; Painemal and Minnis, 2012). A modeling study based on WRFChem is reporting ACI values close to the physical maximum for the SEP region as well as assessing aerosol indirect effects (Yang et al., 2012). However, comprehensive observational ACI calculations have not yet been carried out to date for this region, and an observational quantification of the first aerosol indirect effect is lacking. The aerosol and cloud microphysics interactions component are not easily explored with passive satellite observations. A serious issue is the difficulty in estimating sub-cloud aerosol concentrations from space, so that cloud and aerosol retrievals are not spatially collocated. In situ and land (surface)-based observations are deemed to be more accurate, but different studies report a wide range of estimates of ACI (see McComiskey and Feingold, 2008, for a review). This apparent inconsistency has been explained by dissimilar spatial/temporal resolution of the observations, biases inherent to the retrievals, lack of LWP constraint, and potential regime-dependent differences (McComiskey and Feingold, 2012). We explore these issues for this region, using airborne in situ and remotely-sensed observations, and by comparing the airborne-derived numbers to satellite estimates. 
Table 1. C-130 research flights, time periods, and number of flight samples contributing to the study after thresholds were applied. Local time is approximately UTC-5.

\begin{tabular}{llrr}
\hline Name & 2008 Date & Time (UTC) & $N$ \\
\hline Research Flight 01 (RF01) & 15 October & $17: 47-19: 27$ & 419 \\
Research Flight 02 (RF02) & 18 October & $13: 46-19: 10$ & 2277 \\
Research Flight 11 (RF11) & 9 November & $13: 42-20: 12$ & 284 \\
Research Flight 12 (RF12) & 11 November & $14: 23-20: 55$ & 1025 \\
\hline
\end{tabular}

We take advantage of the high temporal resolution observations collected by the NSF/NCAR aircraft C-130 during the VAMOS Ocean-Cloud-Atmosphere-Land System Regional Experiment (VOCALS-REx, Wood et al., 2011). Other airborne assessments of the first aerosol indirect effect have used microphysical data taken during aircraft soundings to compute vertically-integrated variables such as LWP and $\tau$ (e.g., Twohy et al., 2005). Such an analysis is also performed here using aircraft vertical profiles that were collected during VOCALS-REx. The unprecedented (to our knowledge) airborne remote sensing analysis within this study, however, is potentially capable of providing many more samples. Specifically, we combined daytime aerosol concentration measurements sampled within the marine boundary layer during 10minute subcloud legs, with simultaneous aircraft remotelysensed LWP and $\tau$. The algorithm for retrieving LWP from an airborne millimeter-wave radiometer is documented in Zuidema et al. (2012). The physical algorithm for estimating $\tau$ from combining shortwave irradiances measured by an hemispheric Eppley Precision Spectral Pyranometer combined with a plane-parallel radiative transfer model, is presented here.

\section{Dataset}

Upward-looking airborne radiometers sampled continuously during sub-cloud transects (150-200 m a.s.1.), with a hemispheric field-of-view for the broadband shortwave measurements. The 1.7 degree beam width of the millimeterwavelength G-band (183 GHz) Vapor Radiometer (GVR) corresponds to an $\sim 30 \mathrm{~m}$ horizontal spatial resolution for a typical $500 \mathrm{~m}$ aircraft-to-cloud distance. In contrast, the broadband irradiance measurements sample a horizontal area of $860 \mathrm{~m}(1375 \mathrm{~m})$ as estimated from a viewing angle measured from nadir of $60^{\circ}\left(70^{\circ}\right)$. The sub-cloud aerosol concentration measurements were collected simultaneously by a Passivity Cavity Aerosol Probe (PCASP). Since the $\tau$ retrievals were based on solar transmission calculations, our analysis was limited to daytime flights (when the 1AIE is important). We selected four from a total of six daytime flights performed by the aircraft $\mathrm{C}-130$, with an approximate duration of $8 \mathrm{~h}$ and $1 \mathrm{~Hz}$ sampling (Table 1$)$. The two excluded flights either did not sample much cloud, and/or encountered frequent precipitation, both of which are unfavorable for re- trieving LWP and $\tau$ and do not represent physical realms for which the first aerosol indirect effect is significant.

\subsection{Regional context}

Figure 1 depicts the regional maps of satellite-based $N_{\mathrm{d}}$ and LWP from MODIS-Terra ( 10:30 local time) for the four daytime flights and their respective aircraft trajectories. MODIS LWP and $N_{\mathrm{d}}$ were calculated as functions of $r_{\mathrm{e}}$ and $\tau$, assuming an adiabatic-like stratified cloud, and a linear increase of $r_{\mathrm{e}}$ with height, following Painemal and Zuidema (2011). RF02 (18 October) had the largest $N_{\mathrm{d}}$, with typical values higher than $300 \mathrm{~cm}^{-3}$, indicative of a significant aerosol impact in the cloud properties. For RF01 (15 October), RF11 (9 November), and RF12 (11 November), the high $N_{\mathrm{d}}$ plume covered a smaller area, and was mainly confined to the coast, with the smallest extension during RF11. 18 October (RF02) was a member of the 6-year high- $N_{\mathrm{d}}$ tercile group examined within Painemal and Zuidema (2010). High$N_{\mathrm{d}}$ days were on average more stable near the coast, with thinner clouds, than low- $N_{\mathrm{d}}$ days (Painemal and Zuidema, 2010). Overall, the satellite $N_{\mathrm{d}}$ maps anticipate aircraft sampling of a wide range of aerosol loadings under the same meteorology, which is desired for investigating the first indirect effect. RF01, RF11 and RF12 favored the sampling of coastal regions that were more typically prone to anthropogenic influences (e.g. Bretherton et al., 2010; Painemal and Zuidema, 2010; Allen et al., 2011; Zheng et al., 2011), whereas RF02 sampled offshore clouds that, in this case, still had high $N_{\mathrm{d}}$ values $500 \mathrm{~km}$ offshore.

The surface meteorological pattern (Fig. 2), as expected, is described by a persistent anticyclone and surface winds parallel to the coast with calmer winds within the Arica Bight $\left(20^{\circ} \mathrm{S} 72^{\circ} \mathrm{W}\right)$. More interesting is the case-to-case variability in winds associated with a coastal jet (Muñoz and Garreaud, 2005). For a high- $N_{\mathrm{d}}$ day such as 18 October (RF02), the anticyclone and coastal winds are weaker and boundary layer shallower, than for a day with lower $N_{\mathrm{d}}$ such as 9 November (RF11) (Painemal and Zuidema, 2010; Zheng et al., 2011).

\subsection{Liquid water path (LWP)}

The airborne G-band Vapor Radiometer, with an upward pointing orientation, was used to retrieve LWP. The GVR, designed by ProSensing Inc., measures radiances from 

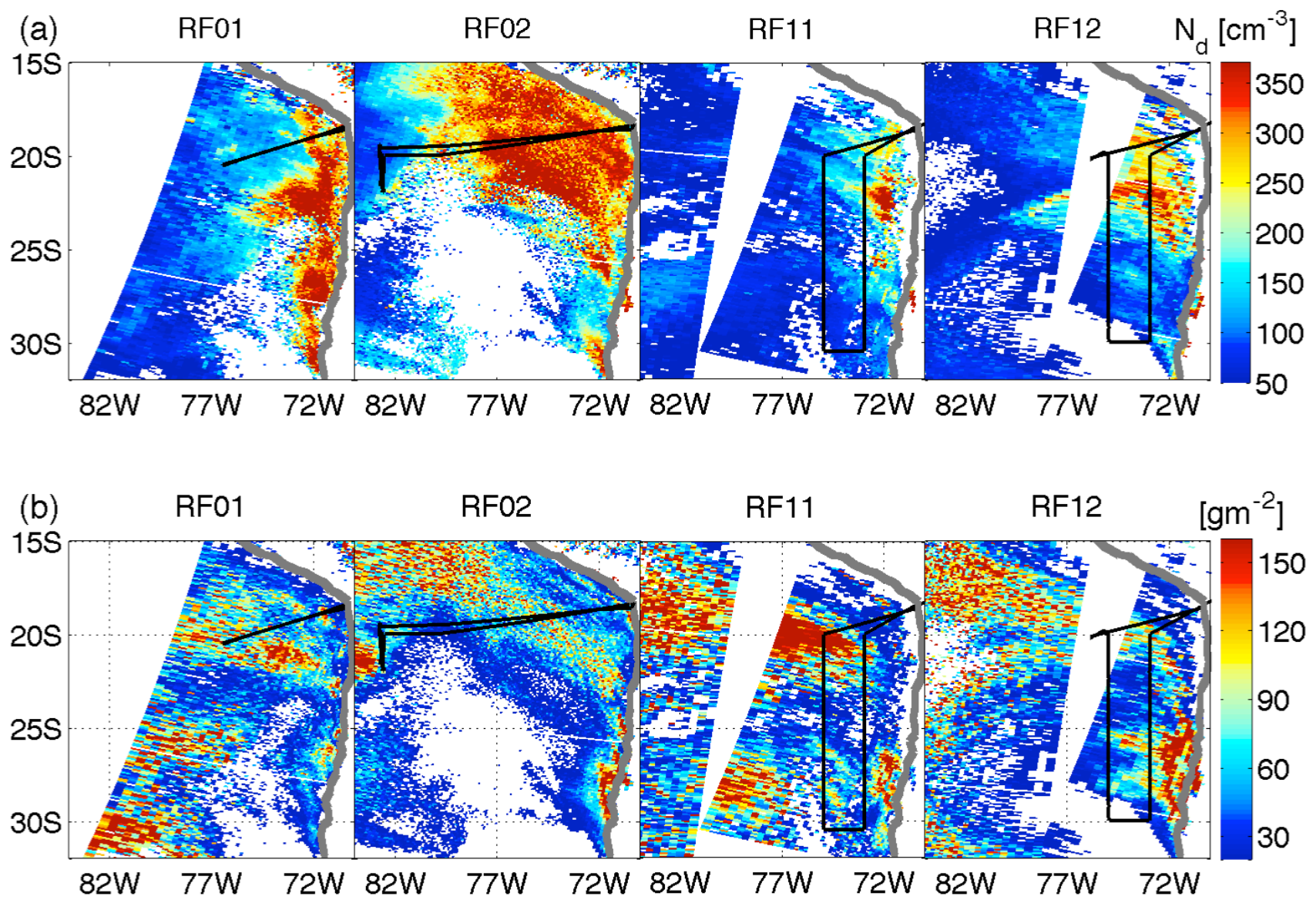

Fig. 1. MODIS-Terra maps for each research flight. (a) $N_{\mathrm{d}}$ and (b) LWP. The black solid lines indicate the aircraft track. The thick gray line represents the coastal line.

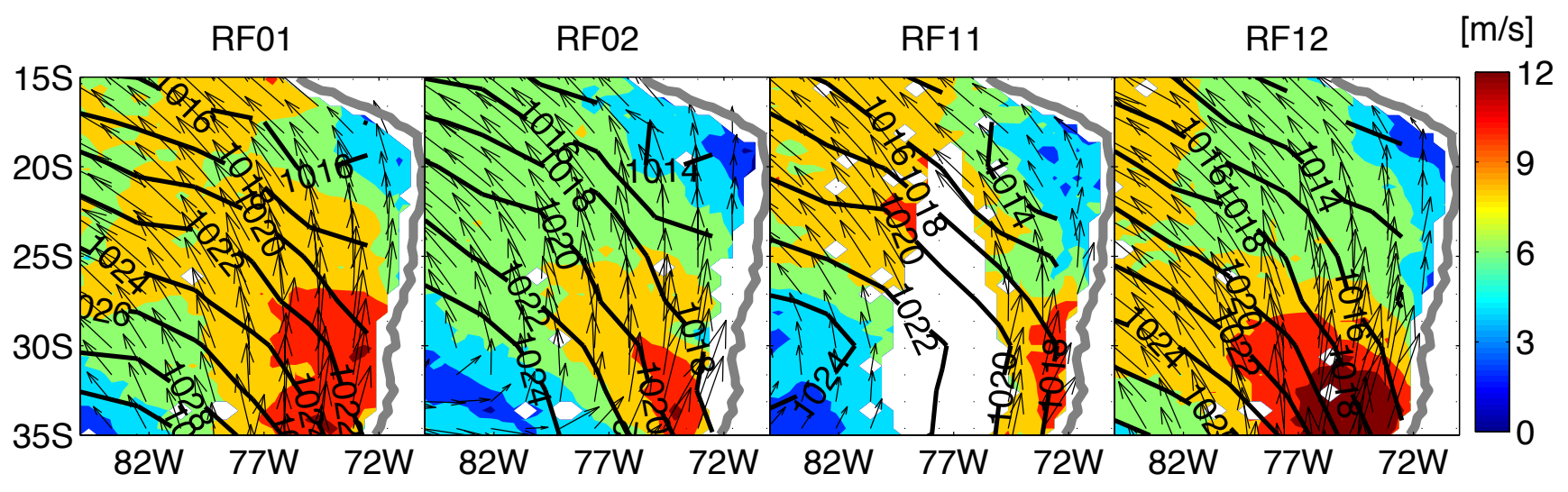

Fig. 2. Daily mean wind direction (arrows) and magnitude (colors) from NASA's Quick Scatterometer (QuikScat). The black contours are the reanalyzed daily sea level pressure from the NCEP/NCAR.

double sideband channels at $\pm 1 \pm 3 \pm 7$ and $\pm 14 \mathrm{GHz}$ from the $183.31 \mathrm{GHz}$ line (Pazmany et al., 2007). The wing-line $\pm 14 \mathrm{GHz}$ band is best suited for retrieving liquid water because of its higher sensitivity to liquid water. The above- aircraft water vapor path was sufficient to saturate the center absorption lines, and independent estimates of water vapor were prescribed to isolate the liquid water absorption signal. The water vapor path (WVP) within the flight level and 


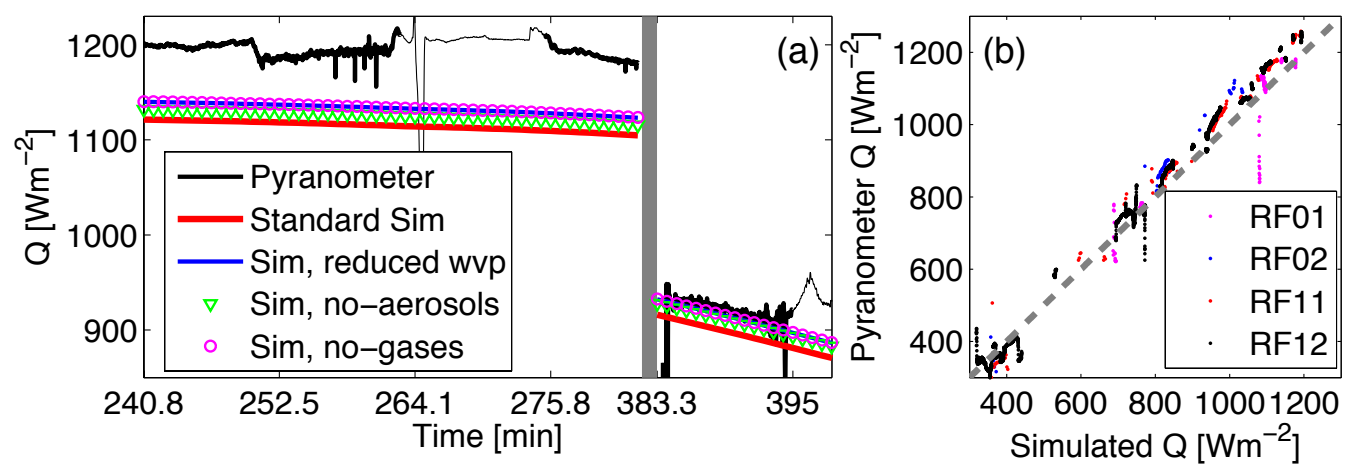

Fig. 3. Simulated and pyranometer irradiances: (a) Time series during RF12. The pyranometer irradiance is denoted by the black line, and the thick black line represents periods with clear-sky conditions. The red line is the standard simulation, whereas the blue line, green triangles, and magenta circles represent the simulations with $50 \%$ reduction in water vapor, pristine conditions, and negligible absorbing gases respectively. (b) Scatterplot between the pyranometer irradiance and the simulated one for above-clouds observations.

the cloud base was estimated from aircraft measurements of water vapor mixing ratio, assuming that the total moisture was conserved up to the lifting condensation level, with an additional adjustment when the boundary layer was decoupled (Zuidema et al., 2012). The in-cloud water vapor was adiabatically calculated. Additionally, the free tropospheric water vapor path was retrieved from the GVR during abovecloud flight legs (free tropospheric WVP did not saturate the absorption lines), and then summed with the boundary-layer WVP to produce the total WVP. The retrieval algorithm iterated between a model-calculated brightness temperature and the observed brightness temperature ( $\pm 14 \mathrm{GHz}$ band) to find the LWP providing the closest brightness temperature match (Zuidema et al., 2012). Comparisons of GVR LWP against its adiabatic counterpart showed good correlations and statistically smaller GVR LWP, which is consistent with an expected but small cloud sub-adiabaticity (Zuidema et al., 2012). A conservative absolute error in the leg-mean LWP was estimated at $20 \mathrm{~g} \mathrm{~m}^{-2}$, with larger uncertainties for precipitating clouds and decoupled boundary layers.

\subsection{Cloud optical thickness $(\tau)$}

The pyranometer-based $\tau$ retrieval relied on the strong dependence of $\tau$ on the downward solar irradiance and the solar zenith angle, with secondary dependences on $r_{\mathrm{e}}$ and the atmospheric composition (Leontyeva and Stamnes, 1994). The algorithm consisted of iterative radiative transfer simulations targeted to find the optimal $\tau$ that matched the pyranometer irradiance. The forward calculations of irradiance were performed with Streamer model (Key and Schweiger, 1998); a versatile DISORT-based radiative transfer model that has been successfully applied to the study of Arctic stratus clouds (e.g. Pinto, 1997; Zuidema et al., 2005). The model employs the Hu and Stamnes (1993) parameterization to calculate the single scattering albedo, volume extinction coefficient, and asymmetry factor from a specified cloud effective radius. The
Streamer simulations applied to the spectral band $0.28 \mu \mathrm{m}-$ $2.91 \mu \mathrm{m}$, which is slightly broader than the spectral band measured by the pyranometer $(0.28 \mu \mathrm{m}-2.8 \mu \mathrm{m})$. This spectral difference was independently examined with the higherspectral-resolution SBDART model (Richiazzi et al., 1998) and found to be an insignificant source of error (less than $1 \mathrm{~W} \mathrm{~m}^{-2}$ ). The solar zenith angle was calculated from the flight UTC time and the aircraft spatial coordinates.

\subsubsection{Model-pyranometer bias}

We first tested the model performance against in situ pyranometer clear-sky observations. We focused on 11 November flight (RF12) measurements collected $\sim 200 \mathrm{~m}$ a.s.l. (subcloud). Two periods with extended clear sky conditions, as determined by the Wyoming cloud lidar, were utilized for the initial assessment. We prescribed the WVP as in Zuidema et al. (2012), and assumed an aerosol optical thickness of 0.05 and a standard McClatchey summer midlatitude profile of atmospheric gases (Fig. 3, red line, standard simulation). The simulated irradiances in Fig. 3a (red line) underestimated the pyranometer observations (black line), especially during the first period (mean bias of $80 \mathrm{~W} \mathrm{~m}^{-2}$ ), but with a reduction later on $\left(20 \mathrm{~W} \mathrm{~m}^{-2}\right)$ at a higher zenith angle.

The rather unexpected model bias was further analyzed by determining the sensitivity of the simulated fluxes to the atmospheric composition. Three additional simulations included cases with $50 \%$ reduction in WVP, pristine conditions without aerosols, and negligible absorbing gases (ozone and tracing gases) (Fig. 3a, blue line, green triangles, and magenta circles respectively). While reductions in any atmospheric quantity produced larger shortwave fluxes, these changes could not explain why the model underestimated the observed irradiance.

Given the scarcity of clear-sky observations, we carried out a more systematic analysis of the pyranometermodel bias using above-cloud measurements and simulated 
Table 2. Regression values used to correct the pyranometer irradiance $Q_{\text {pyr-adj }}=a \cdot Q_{\text {pyr }}+b$.

\begin{tabular}{lrr}
\hline & a & $b\left[\mathrm{~W} \mathrm{~m}^{-2}\right]$ \\
\hline RF01 & 0.97 & 25 \\
RF02 & 0.92 & 12 \\
RF11 & 0.9 & 68 \\
RF12 & 0.91 & 41 \\
\hline
\end{tabular}

irradiances for the four research flights considered in this investigation. We prescribed a mean free tropospheric water vapor path of $3 \mathrm{~mm}$, standard values of atmospheric gases for a summer mid-latitude atmosphere, and a fixed aerosol optical thickness at 0.05 . Fig. 3 b shows the relationship between simulated and observed fluxes at heights between 1400$1700 \mathrm{~m}$ a.s.1. Although both fluxes correlated well, the simulated ones were lower, with a bias that increased with $Q$, as it was anticipated in Fig. 3a.

The persistent negative offset in our simulations was not consistent with an aircraft attitude (pitch/roll) effect, since that would produce both anomalous high and low pyranometer irradiances relative to observations collected over a fixed horizontal plane. We suspected potential pyranometer calibration errors that could not be verified, as we did not count on assessments of the pyranometer performance prior and after the flights. Nevertheless, calibration problems were plausible as previous airborne field experiments noted systematic instrument offsets (e.g. Kato et al., 1997; Bush et al., 2000). For instance, comparison of five uncalibrated Eppley pyranometers during the Atmospheric Radiation Measurements Enhanced Shortwave Experiment (ARESE) revealed irradiance differences of up to $5 \%$ (Kato et al., 1997).

Since the inconsistency between modeled and measured irradiance might severely affect the cloud optical thickness retrievals, we adjusted the pyranometer irradiance $\left(Q_{\text {pyr-adj }}\right)$ through a linear regression that fitted above-clouds pyranometer fluxes with the simulated clear-sky irradiances (Eq. 7).

$Q_{\text {pyr-adj }}=a \cdot Q_{\text {pyr }}+b$

$Q_{\text {pyr }}$ indicates the measured pyranometer irradiance. Typically the slope $a$ encompasses values between 0.9 and 0.97 (Table 2). This adjustment proved to significantly reduce the bias in Fig 3a to amounts smaller than $10 \mathrm{~W} \mathrm{~m}^{-2}$. Hereafter, we only make use of the adjusted pyranometer irradiance (denoted as $Q_{\text {pyr }}$.

\subsubsection{Retrieval algorithm}

Inputs for the retrieval algorithm included the WVP as described in Sect. 2.3.1, constant aerosol optical thickness of 0.05 , and McClatchey mid-latitude summer profiles for the ozone and trace gases (Key and Schweiger, 1998). The sim-

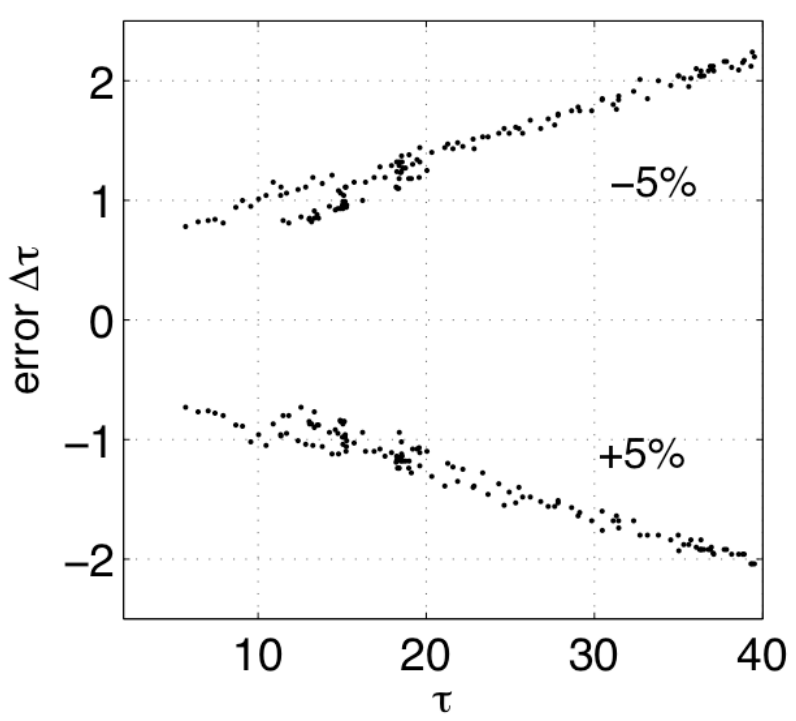

Fig. 4. Error in $\tau$ associated with a $5 \%$ uncertainty in the pyranometer measurements.

ulations were further simplified by assuming a vertically homogeneous cloud with a constant $r_{\mathrm{e}}$. In the first stage of the algorithm, we prescribe initial $\tau\left(\tau^{*}\right)$ and $r_{\mathrm{e}}\left(r_{\mathrm{e}}^{*}\right)$ and perform 2-stream simulations to estimate the irradiance $Q\left(r_{\mathrm{e}}^{*}, \tau^{*}\right)$. The initial $r_{\mathrm{e}}^{*}$ and $\tau^{*}$ were adiabatically calculated from GVR LWP and a simple empirical $N_{\mathrm{d}}$ proxy expressed as $N_{\mathrm{d}}=50+0.5 \cdot N_{\mathrm{a}}$ (J. R. Snider, personal communication, 2012). If the absolute value $\left|\mathrm{Q}\left(r_{\mathrm{e}}^{*}, \tau^{*}\right)-\mathrm{Q}_{\mathrm{pyr}}\right|>3 \mathrm{~W} \mathrm{~m}^{-2}$, then $\tau^{*}$ is increased (decreased) by 0.04 when $Q\left(r_{\mathrm{e}}^{*}, \tau^{*}\right)$ is larger (smaller) than $Q_{\mathrm{pyr}}$, and the irradiance is calculated again with the prescribed $r_{\mathrm{e}}^{*}$. When $\left|Q\left(r_{\mathrm{e}}^{*}, \tau^{*}\right)-Q_{\mathrm{pyr}}\right|<3 \mathrm{~W} \mathrm{~m}^{-2}$ the iteration ends and $r_{\mathrm{e}}^{*}$ is upgraded to $r_{\mathrm{e}} *=\frac{2}{3 \tau *} \cdot \mathrm{LWP}$ (valid for vertically constant water content and $r_{\mathrm{e}}$ ), and the retrieved $\tau^{*}$ and $r_{\mathrm{e}}^{*}$ are used for the next loop. Although the algorithm is insensitive to the initial $r_{e}^{*}$ and $\tau^{*}$, appropriate values can considerably reduce the number of iterations.

A second two-stream loop, identical to the previous one, is made with the upgraded $r_{\mathrm{e}}^{*}$ and $\tau^{*} . r_{\mathrm{e}}^{*}$ is upgraded for the last time at the end of the loop, and the pair $r_{\mathrm{e}}^{*}-\tau^{*}$ is used for the next and final iteration. For the final loop, we expanded the number of discrete ordinates to eight streams, and continued the simulations until the simulated fluxes differ in $3 \mathrm{~W} \mathrm{~m}^{-2}$ from the observed fluxes.

\subsection{3 $\tau$ Uncertainties}

We explore the impact of the following uncertainties in $\tau$ : vertically homogeneous cloud assumption, errors in water vapor and liquid water path, and errors in the pyranometer observations. The effect of assuming a constant water content and $r_{\mathrm{e}}$ with height is assessed by retrieving $\tau$ using synthetic irradiances calculated for a cloud with an adiabatic vertical stratification. We find a small $\tau$ bias, with $\tau$ exceeding 


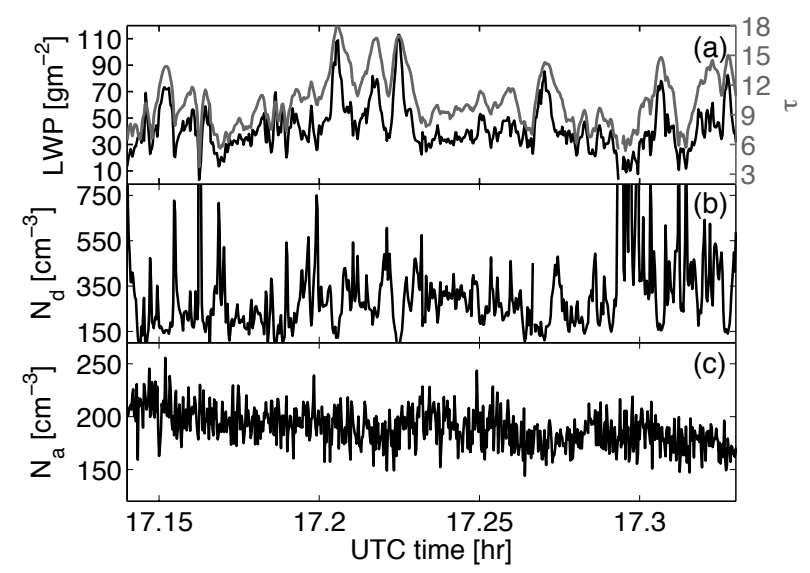

Fig. 5. Example of time series during 18 October research flight (RF02, subcloud leg 5): (a) GVR LWP (black) and $\tau$ (gray), (b) $N_{\mathrm{d}}$ from Eq. (9), (c) accumulation mode aerosol concentration $N_{\mathrm{a}}$.

its adiabatic counterpart by 0.2 , consistent with a lack of sensitivity to the vertical profile described in Brenguier et al. (2000) but for narrow band measurements. $A \pm 30 \%$ error in the specified WVP would produce typical $\tau$ bias smaller than $4 \%$, in agreement with Leontyeva and Stamnes (1994). In addition, we also analyze the effect of uncertainties in LWP error by assuming $30 \%$ variations (equivalent to $30 \%$ variations in $r_{\mathrm{e}}$ ). We find that the mean error in $\tau$ is close to $5 \%$, with a negative (positive) bias when LWP is biased low (high).

We finally explore the effect of the pyranometer uncertainties in the retrieved $\tau$. We assume a conservative error of $5 \%$ in the pyranometer signal, a value that accounts for the mean error that could arise from the mismatch between observations and the radiative model found in Sect. 2.3.1. After applying the retrieval algorithm to the modified pyranometer fluxes, we found biases between $15 \%(\Delta \tau=0.6)$ and $5 \%$ $(\Delta \tau=2)$ for a range of $\tau$ between 4 and 40 respectively (Fig. 4). Based on these results, we estimate a conservative mean $\tau$ uncertainty near $10 \%$.

\subsubsection{Suitability of plane-parallel assumption}

The success of the plane-parallel Streamer calculation depends on the spatial homogeneity of the stratocumulus deck. This was investigated using a heterogeneity index $(\mathrm{H} \sigma)$ calculated as the ratio of the standard deviation to the mean LWP for a 11 second moving window $(1.1 \mathrm{~km})$. This definition is similar to a previously-used satellite-derived $\mathrm{H} \sigma$ that was spatially calculated from the $0.86 \mu \mathrm{m}$ MODIS visible reflectance (e.g. Zhang and Platnick, 2011; Di Girolamo et al., 2010). The $\mathrm{H} \sigma$ calculated here encompassed values between $0-1$ (consistent with satellite estimates), with a mean $\mathrm{H} \sigma$ of 0.2 and a standard deviation of 0.15 . Zhang and Platnick (2011) found evidence of 3-D effects in MODIS retrievals for MODIS-based $\mathrm{H} \sigma$ values larger than 0.3. If our LWPbased results can be approximately compared to the satellitebased $\mathrm{H} \sigma$, the LWP-based $\mathrm{H} \sigma$ values do suggest that the clouds investigated here were mostly homogeneous. In addition, the standard deviation of the logarithm of LWP for the combined four flights is equal to 0.22 , lower than the value found by Cahalan et al. (1994) based on 18 days of microwave LWP data from Californian stratus. The lower value reported here reflects the larger dataset examined within $\mathrm{Ca}-$ halan et al. (1994), equivalent to $\sim 8500 \mathrm{~km}$ transect, or a $\sim 15$-fold increase, as well as the greater frequency of lowerLWP clouds in our dataset.

\subsection{LWP- $\tau$ consistency and general overview}

Figure 5 shows a ten minutes time series during RF02 of the variables used to compute the ACI: GVR LWP and $\tau$ (Fig. 5a), $N_{\mathrm{d}}$ (Fig. 5b, Eq. 9) and $N_{\mathrm{a}}$ (Fig. 5c). The near 10 min sampling in Fig. 5 is equivalent to a $60 \mathrm{~km}$ transect (mean aircraft speed of $100 \mathrm{~m} \mathrm{~s}^{-1}$ ), which would explain the apparent high variability in the time series. LWP and $\tau$ show the expected correlation (Sect. 2.4), but with a less variable $\tau$. This is because the pyranometer collects hemispheric incident solar radiation, and therefore, the retrieved $\tau$ is representative of a broad $(\sim 1 \mathrm{~km})$ cloudy area. In general, spatial/temporal changes in $\tau$ attributed to $N_{\mathrm{a}}$ are difficult to observe because of the boundary layer control in the evolution of the cloud properties. This further stresses the importance of investigating the $\tau-N_{\mathrm{a}}$ interactions within a constant dynamical configuration, established in this study by constraining LWP. Further discussion on the remote sensing-based $N_{\mathrm{d}}$ will be presented in Sect. 2.4.

We determined the physical consistency of the remotely sensed LWP- $\tau$ pairs through comparisons to their in situ counterparts. We focused on cloud conditions most conducive to first aerosol indirect effects: well-coupled, unbroken clouds with little precipitation. Thus, we eliminated samples with lidar-based cloud base height and lifting condensation level differences larger than $150 \mathrm{~m}$ (Jones et al., 2011). The effect of broken clouds in the pyranometer field of view was reduced by removing samples that did not occur $7 \mathrm{~s}$ prior and after cloudy observations $(1.4 \mathrm{~km}$ cloudy horizontal transect). Drizzling cases were excluded using a columnmaximum radar reflectivity threshold of $-17 \mathrm{dBZ}$, equivalent to a drizzle rate of $0.1 \mathrm{~mm} \mathrm{day}^{-1}$ (Comstock et al., 2004). We furthermore only considered samples with LWP $>20 \mathrm{~g} \mathrm{~m}^{-2}$ and $\tau>2$, to reduce the measurements with larger relative retrieval uncertainties. The aforementioned screening was satisfied by 4005 samples, of which $80 \%$ were collected during RF02 and RF12 (Table 1). Fig. 6a depicts the relationship between $\tau$ and LWP for both remote-sensing and in situ variables during the four daytime flights (black dots and red circles respectively). Aircraft-based LWP and $\tau$ were calculated by vertically integrating the profile liquid water content and the extinction coefficient, respectively. The 

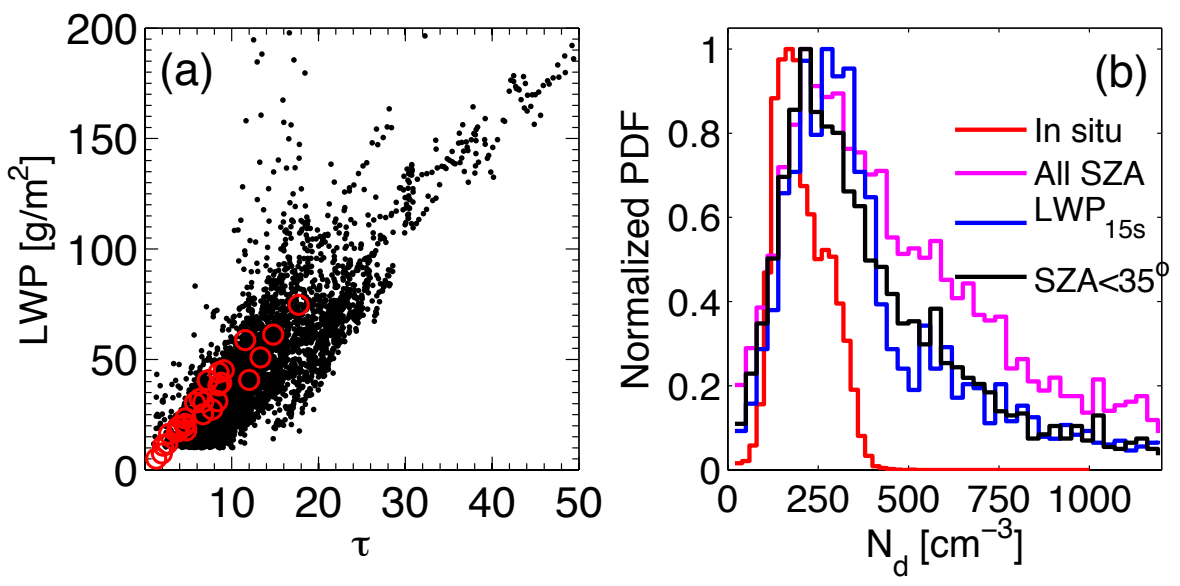

Fig. 6. (a) LWP versus $\tau$. Black dots represent the remote sensed values, and the red circles are the values derived from the cloud probes. (b) Normalized probability density function (PDF) for the remote sensing-based $N_{\mathrm{d}}$ (magenta, black, and blue lines, Eq. (9)) and the in situ $N_{\mathrm{d}}$ obtained during in-cloud legs (red line). The remote sensing-based $N_{\mathrm{d}}$ was estimated from samples with LWP $>20 \mathrm{~g} \mathrm{~m}^{-2}$ (magenta line) and solar zenith angle smaller than $35^{\circ}$ (black line). Blue line corresponds to $N_{\mathrm{d}}$ calculated with the 15-s averaged LWP. Remote sensing-based $N_{\mathrm{d}}$ retrievals were calculated for $\tau>2, \mathrm{LWP}>20 \mathrm{~g} \mathrm{~m}^{-2}$, overcast at $1.4 \mathrm{~km}$ scale, and column-maximum reflectivity $<-17 \mathrm{dBZ}$.

extinction coefficient was derived from the second moment of the droplet spectra and assuming a constant extinction efficiency of 2 (Painemal and Zuidema, 2011). In situ and remote sensing observations showed a high LWP- $\tau$ correlation with an agreement in the slope, indicating the physical consistency of the retrievals.

We carried out an additional indirect retrieval assessment by comparing a histogram of in situ $N_{\mathrm{d}}$ to an adiabatic-like $N_{\mathrm{d}}$, derived from the remote sensing observations as follows:

$N_{\mathrm{d}}=0.05789\left[\mathrm{~g}^{2} \mathrm{~cm}^{-6}\right] \cdot \frac{\Gamma^{1 / 2}}{k} \cdot \frac{\tau^{3}}{\mathrm{LWP}^{5 / 2}}$

where $\Gamma$ is the local stratification of the water content with height, and $k$ is the ratio between the cube of the effective radius and the volume radius of the droplet size distribution. This $N_{\mathrm{d}}$ is similar to the one applied within Painemal and Zuidema (2011) to MODIS data, but cast in terms of LWP and a non-constant $\Gamma$. $\Gamma$ corresponded to the adiabatic lapse rate, calculated every second from remote-sensed cloud base height and temperature, and multiplied by 0.9 , a factor that accounted for the mean sub-adiabaticity of the clouds, according to both in situ and aircraft remote sensed retrievals for the analyzed flights. For k, we selected a constant mean value of 0.88 at the cloud top derived from the aircraft cloud probes. Qualitatively, the modes of the $N_{\mathrm{d}}$ histograms (Fig. 6b, red a magenta lines) agreed relatively well, with values near $180-220 \mathrm{~cm}^{-3}$. Nevertheless, the remotely-sensed airborne $N_{\mathrm{d}}$ had more cases with concentrations larger than $450 \mathrm{~cm}^{-3}$ (magenta line), values rarely observed by the C130 cloud probes. This could imply a LWP underestimate or a cloud optical depth overestimate. Differences in the instruments field of view, manifested in a higher temporal variability in LWP, are also a factor to take into account. For instance, we observed in Fig. 5 that local minima in LWP led to a sharp increase in $N_{\mathrm{d}}$ (Fig. $5 \mathrm{~b}$ ). The time series also indicated that some cases with high $N_{\mathrm{d}}$ were associated with small LWP $\left(<30 \mathrm{~g} \mathrm{~m}^{-2}\right.$, Fig. 5b, 17:30-17:33 UTC).

Since our samples were associated with solar zenith angles (SZA) ranging between $10^{\circ}$ to $50^{\circ}$, we also partially explored the dependence of the remote-sensed $N_{\mathrm{d}}$ on SZA, by removing samples with SZA larger than $35^{\circ}$. This screening improved the remote-sensed histogram through a reduction of samples with very large $N_{\mathrm{d}}$ (Fig. 6b, black lines). This may demonstrate the sensitivity of these retrievals to threedimensional radiative transfer effects. At low zenith angles when the Sun is closer to overhead, downward photon diffusion can increase the irradiance measured below a cloud relative to a plane-parallel calculation, leading to an underestimate in the cloud optical depth (e.g., Zuidema and Evans, 1998). For high zenith angles, brightening/shadowing effects from single-scattering off of cloud top inhomogeneities can generate a mean overestimate of cloud optical depth. Three-dimensional radiative transfer effects are expected to be small for SZA between 10 and 35 degrees (Kato and Marshak, 2009), however, and reduced relative to other SZAs. Another plausible explanation might be that the Eppley radiometer performed better at lower SZA. For this study, we primarily highlight the sensitivity of the analysis to SZA, and further limit our investigation to samples with SZA $<35^{\circ}$.

A second $N_{\mathrm{d}}$ estimate was performed by using a 15 -s moving average LWP $\left(\overline{\mathrm{LWP}}_{15 \mathrm{~s}}\right)$, which better accounts for the field of view of the pyranometer. The new $N_{\mathrm{d}}$ histogram (Fig. 6b, blue line) depicts a modest reduction in $N_{\mathrm{d}}$, but with a mode that increases relative to $N_{\mathrm{d}}$ calculated with native resolution variables. 
Table 3. Variables and instrument dependences.

\begin{tabular}{ll}
\hline Measurements & Instruments \\
\hline LWP & G-band Vapor Radiometer $[183 \mathrm{GHz}]$ \\
$\tau$ & Eppley Precision Spectral Pyranometer \\
& {$[0.28-2.80 \mu \mathrm{m}]$} \\
Aerosols, $N_{\mathrm{a}}$ & DMT's Passive Cavity Aerosol Spectrometer Probe \\
& (PCASP), sizes: [0.1 $\mu \mathrm{m} 3.0 \mu \mathrm{m}]$ \\
Radar Reflectivity & Wyoming Cloud Radar $[94 \mathrm{GHz}]$ \\
Cloud base height & Wyoming Cloud Lidar \\
$N_{\mathrm{d}}$ & $f($ LWP $\tau)$ \\
\hline
\end{tabular}
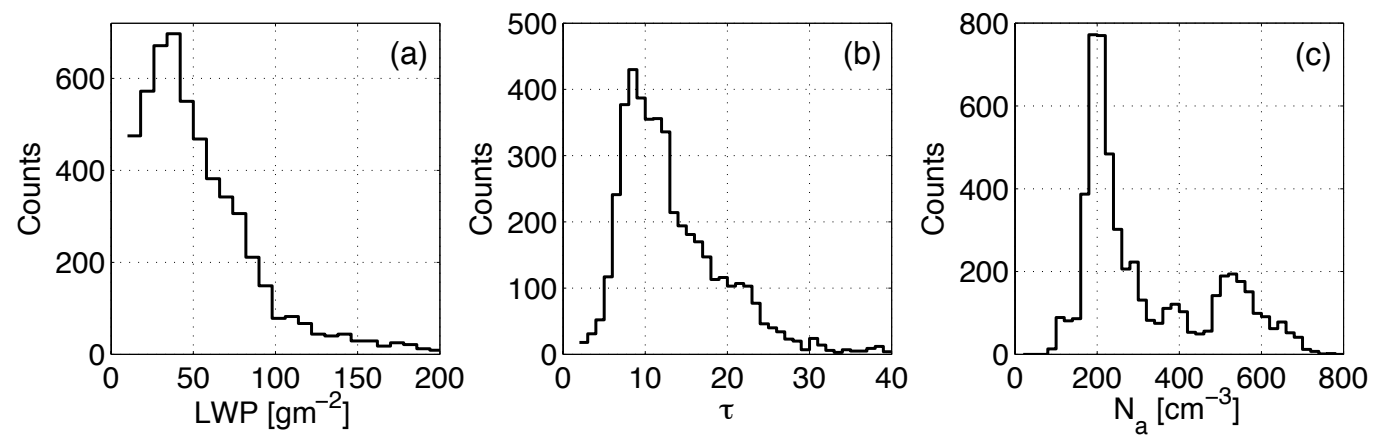

Fig. 7. Histograms for the four research flights: (a) LWP, (b) $\tau$, and (c) $N_{\mathrm{a}}$. Histograms were calculated for: $\mathrm{LWP}>20 \mathrm{~g} \mathrm{~m}{ }^{-2}, \tau>2$, $\mathrm{SZA}<35^{\circ}$, overcast at $1.4 \mathrm{~km}$ scale, and column-maximum reflectivity $<-17 \mathrm{dBZ}$.

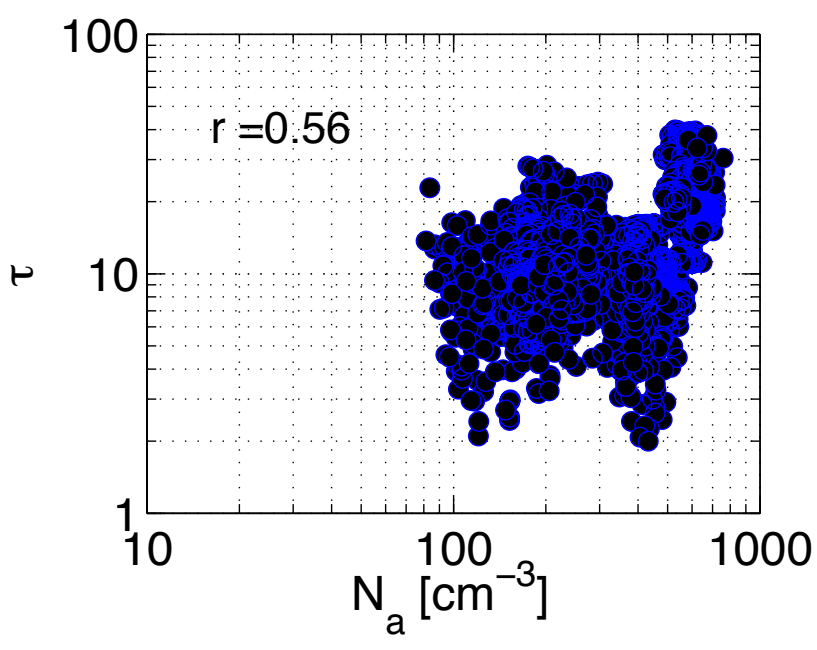

Fig. 8. Scatterplot between $N_{\mathrm{a}}$ and $\tau$.

We emphasize that the retrieved $N_{\mathrm{d}}$ was primarily used to indicate the level of physical agreement of the $\tau$-LWP pair, and that the retrieved $N_{\mathrm{d}}$ was not explicitly included in the calculation of ACI $\tau$ or $S_{R-\tau}$. We did, however, use $N_{\mathrm{d}}$ as a threshold on the ACI $\tau$ and $S_{R-\tau}$ calculations, in this way examining the sensitivity of the ACI $\tau$ and $S_{R-\tau}$ calculations to the physical agreement of the $\tau$-LWP pair. The summed

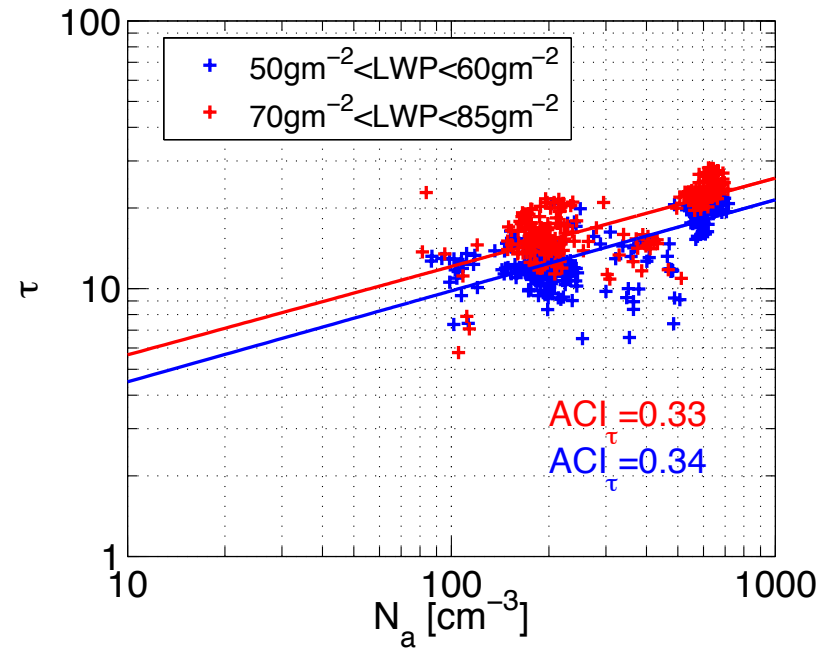

Fig. 9. Scatterplot between $N_{\mathrm{a}}$ and $\tau$. Solid lines are the linear fit for each LWP bin.

probability density functions for LWP, $\tau$, and $N_{\mathrm{a}}$ for the four selected flights, with all constraints met $\left(\mathrm{LWP}>20 \mathrm{~g} \mathrm{~m}^{-2}, \tau\right.$ $>2$, SZA $<35^{\circ}$, overcast at $1.4 \mathrm{~km}$ scale, column-maximum reflectivity $<-17 \mathrm{dBZ}$ ), are depicted in Fig. 7. Mode values for LWP, $\tau$, and, $N_{\mathrm{a}}$ are $40 \mathrm{~g} \mathrm{~m}^{-2}, 8$, and $230 \mathrm{~cm}^{-3}$ respectively. Mean LWP and $\tau\left(50 \mathrm{~g} \mathrm{~m}^{2}\right.$ and 12.6) are fairly 


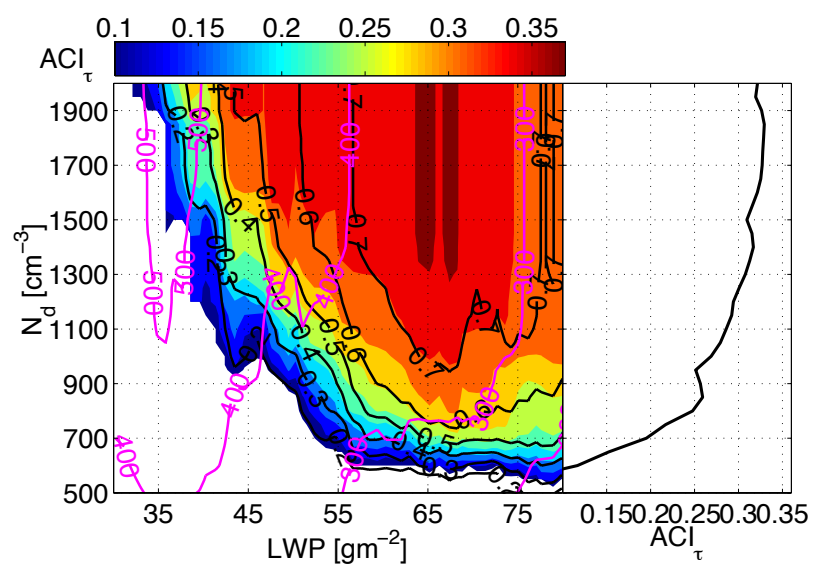

Fig. 10. ACI $\tau$ as a function of LWP and for different upper $N_{\mathrm{d}}$ thresholds (left panel). Black and magenta contours indicate the linear correlation and number of samples per bin respectively. ACI $\tau$ and correlations are statistically significant at the $99.9 \%$ confidence level according to a one-tailed Student's $\mathrm{t}$ test. The right panel corresponds to the average $\mathrm{ACI} \tau$ per $N_{\mathrm{d}}$ threshold.

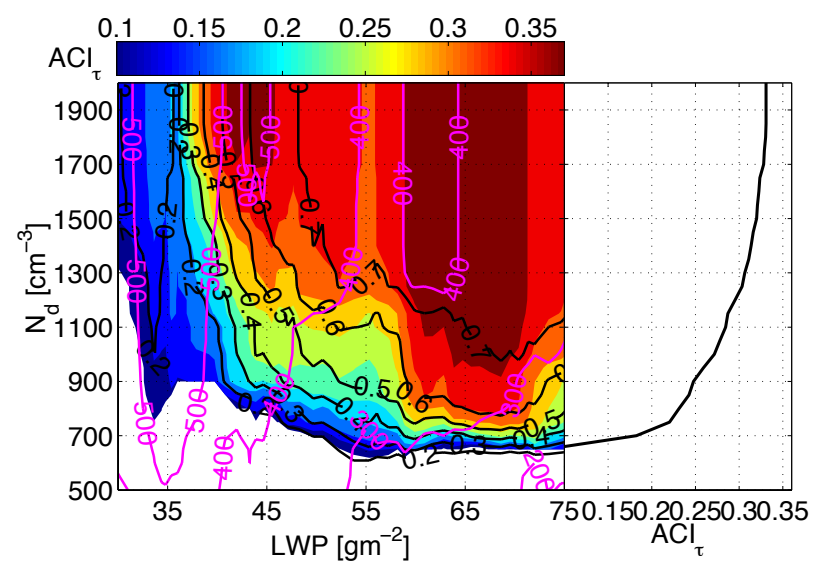

Fig. 11. As in Fig. 10, but for a 15-s LWP running mean.

consistent with a satellite climatology that shows the largest (smallest) $\tau$ (LWP) along the Chile coast (Painemal and Minnis, 2012).

\section{Results}

With available estimates of $\tau$ and LWP, simultaneous PCASP aerosol observations completed the set of variables needed to calculate $\mathrm{ACI}_{\tau}$. The variables and dependencies used in this investigation are listed in Table 3. The relationship between $\tau$ and $N_{\mathrm{a}}$, for the four flights, and irrespective of LWP, is depicted in Fig. 8. As expected, we found a positive correlation $(r=0.56)$ with magnitudes for $N_{\mathrm{a}}$ within $70-800 \mathrm{~cm}^{-3}$. The absence of smaller $N_{\mathrm{a}}$ was explained by the removal of drizzling samples $(>-17 \mathrm{dBZ})$ in our dataset.
While the high correlation does show a link between aerosol concentration and cloud optical properties, the next step is to isolate the aerosol impact from the effect of the cloud macrophysical properties. This was done by imposing LWP binning.

\subsection{ACI calculations}

Our simple approach was to compute ACI $\tau$ for different LWP intervals, and calculate the slope between $\ln \left(N_{\mathrm{a}}\right)$ and $\ln (\tau)$ (McComiskey et al., 2009). We performed the regressions using an iterative reweighted least square fit, with a bisquare weighting function (Street et al., 1988), to reduce the effect of outliers.

Figure 9 illustrates ACI $\tau$ differences between two LWP partitions. For both bins, ACI $\tau$ reached or slightly surpassed the upper physical bound $\left(0.33\right.$ and 0.34 for $70-80 \mathrm{~g} \mathrm{~m}^{-2}$ bin, and $50-60 \mathrm{~g} \mathrm{~m}^{-2}$ bins respectively). The ACI dependence on LWP was more systematically evaluated by calculating $\mathrm{ACI} \tau$ for a set of LWP bins defined as:

$$
\begin{aligned}
& \operatorname{Bin}_{i}=\left[\begin{array}{ll}
0.88 \cdot \mathrm{LWP}_{i} & 1.12 \cdot \mathrm{LWP}_{i}
\end{array}\right] \\
& \mathrm{LWP}_{i}=30,31, \ldots .80 \mathrm{~g} \mathrm{~m}^{-2}
\end{aligned}
$$

The relationship in (10) is equivalent to defining a bin width $24 \%$ the size of the geometrical center of the bin $\mathrm{LWP}_{i}$. This bins width was selected because it yielded a relatively similar number of samples among bins. Although only five bins did not overlap each other (e.g. 30, 39, 50, 64, and $80 \mathrm{~g} \mathrm{~m}^{-2}$ bins), we also calculated ACI $\tau$ by shifting the bin center every $1 \mathrm{~g} \mathrm{~m}^{-2}$ (Eq. 10), in order to show the transition of ACI $\tau$ with more continuous variations in LWP, and explore the robustness of the calculation for any given $\mathrm{LWP}_{i}$. In addition, the sensitivity of ACI $\tau$ to $N_{\mathrm{d}}$ was studied by removing samples linked to $N_{\mathrm{d}}$ larger than some arbitrary thresholds.

Figure 10 illustrates the dependence of ACI $\tau$ on LWP and $N_{\mathrm{d}}$, with slopes and correlations statistically significant at the $99.9 \%$ confidence level according to a one tailed Student's t-test. For high $N_{\mathrm{d}}$ thresholds ACI $\tau$ fluctuated between $0.2-0.36$, with larger values for LWP near $55-75 \mathrm{~g} \mathrm{~m}^{-2}$, an interval that also possessed the largest correlation (0.6-0.7, black contours). The removal of samples with $N_{\mathrm{d}}$ larger than $1100 \mathrm{~cm}^{-3}$ mainly affected the smaller LWPs. A further reduction in $N_{\mathrm{d}}$ produced $\mathrm{ACI} \tau$ that increased with LWP, with values closely bounded by the upper physical limit (0.33). More stringent $N_{\mathrm{d}}$ thresholds $\left(N_{\mathrm{d}}<700 \mathrm{~cm}^{-3}\right)$ reduced the Na- $\tau$ correlation, and yielded a mean $\mathrm{ACI} \tau<0.2$, whereas the slopes became statistically insignificant when LWP $<55 \mathrm{~g} \mathrm{~m}^{-2}$. The ACI $\tau$-LWP dependence was relatively insensitive to the selected bin size, with a bin widening producing a modest increase in $\mathrm{ACI} \tau$ (not shown).

We further repeated the previous analysis but applying a 15 -s moving average to LWP $\left(\overline{\mathrm{LWP}}_{15 \mathrm{~s}}\right)$ and $N_{\mathrm{a}}(\sim 1.5 \mathrm{~km}$ equivalent scale). ACI $\tau$ maps obtained with $\overline{\mathrm{LWP}}_{15} \mathrm{~s}$ and averaged $N_{\mathrm{a}}$ are depicted in Fig. 11. The overall $N_{\mathrm{a}}-\tau$ 


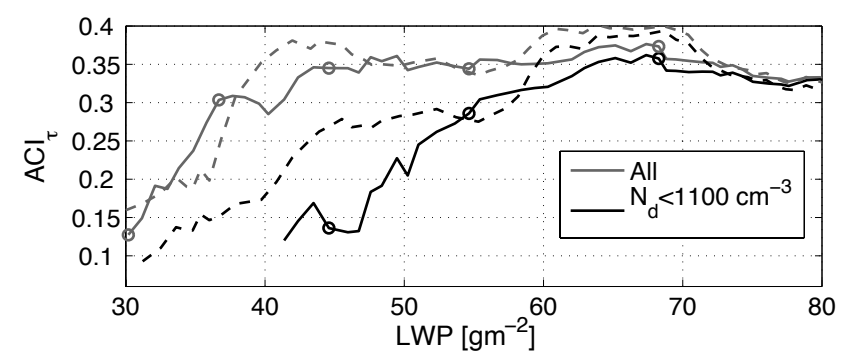

Fig. 12. ACI $\tau$ as a function of LWP bins. Cases with $N_{\mathrm{d}}$ smaller than $1100 \mathrm{~cm}^{-3}$ and irrespective of $N_{\mathrm{d}}$ are denoted by black and gray lines, respectively. Dashed lines indicate $\mathrm{ACI} \tau$ calculated with a 15 -second running mean LWP and $N_{\mathrm{a}}$. Values are statistically significant according to a Student's t test at the $99 \%$ confidence level. Circles indicate bins without overlapping.

correlation and number of samples increased in Fig. 11 relative to the native resolution counterpart (Fig. 10).

The dependencies of ACI $\tau$ on LWP and $N_{\mathrm{d}}$ are more clearly depicted in Fig. 12 for two different cases: ACI $\tau$ estimated irrespective of $N_{\mathrm{d}}$ (gray lines), and $\mathrm{ACI} \tau$ for $N_{\mathrm{d}}<1100 \mathrm{~cm}^{-3}$ (black line). Dashed lines are the estimates derived with $\overline{\mathrm{LWP}}_{15} \mathrm{~s}$. As in Fig. 10, Fig. 12 shows that ACI $\tau$ increased as the imposed $N_{\mathrm{d}}$ threshold was relaxed. All- $N_{\mathrm{d}}$ $\mathrm{ACI} \tau$ yielded magnitudes that fluctuated near the physical maximum $\left(0.3-0.36\right.$, for $\left.\mathrm{LWP}>35 \mathrm{~g} \mathrm{~m}^{-2}\right)$. Although ACI $\tau$ for $N_{\mathrm{d}}<1100 \mathrm{~cm}^{-3}$ increased with LWP, the $N_{\mathrm{a}}-\tau$ correlation decreased to coefficients smaller than 0.45 , especially for LWP $<55 \mathrm{~g} \mathrm{~m}^{-2}$. Moreover, the decreased sensitivity of ACI $\tau$ to $N_{\mathrm{d}}$ for LWP larger than $60 \mathrm{~g} \mathrm{~m}^{-2}$ suggests that our results are more robust for that LWP interval.

Other observational studies have reported a more pronounced decrease in ACI $\tau$ with LWP (Kim et al., 2008; McComiskey et al., 2009) than is reported here. The ACI decrease was attributed to collision/coalescence processes for their larger LWP values (ranges of 50-150 $\mathrm{g} \mathrm{m}^{-2}$ ). For our samples, collision/coalescence processes seem less likely given a mean LWP $<80 \mathrm{~g} \mathrm{~m}^{-2}$ and a requirement that the column-maximum reflectivity be $<-17 \mathrm{dBZ}$. A calculation of the coalescence loss rate for a cloud with $-17 \mathrm{dBZ}$ and $N_{\mathrm{d}}$ of $200 \mathrm{~cm}^{-3}$ yielded a modest 14 droplets $\mathrm{cm}^{-3} \mathrm{day}^{-1}$, using the parameterization of Wood (2006). The question that remains is whether the increase of ACI with LWP reflects an actual aerosol activation enhancement. A weak positive LWP-vertical velocity relationship was found in this dataset $(r=0.11)$, consistent with increased aerosol activation. The results are also consistent with those from an adiabatic parcel model (McComiskey and Feingold, 2012).

$\mathrm{ACI} \tau$ calculated with $\overline{\mathrm{LWP}}_{15 \mathrm{~s}}$ (Fig. 12, dashed lines) yielded slightly larger but less homogeneous transitions with liquid water path. The effects of the smoothing inherent to the cloud optical depth retrieval, and of the additional LWP smoothing $\left(\overline{\mathrm{LWP}}_{15} \mathrm{~s}\right)$, is to reduce the variance within the

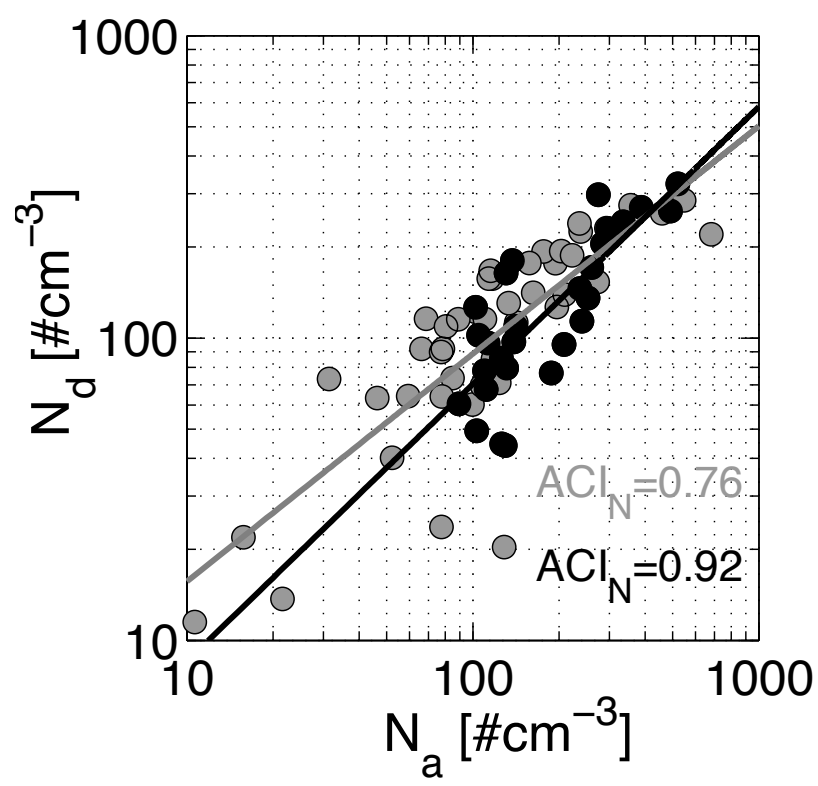

Fig. 13. Scatterplot between $N_{\mathrm{a}}$ and in situ $N_{\mathrm{d}}$. Gray circles correspond to samples collected during all the research flights performed by the C-130 aircraft. Black circles represent those samples collected during the four research flights investigated here.

dataset, increasing the correlation between optical depth aerosol pairs (McComiskey and Feingold, 2012).

The remote-sensing-based magnitudes of ACI $\tau$ were compared against that derived from the aerosol and cloud probe measurements. Since the aerosol probe PCASP was not suited for in-cloud aerosol sampling, we used below cloud measurement instead. We averaged $30 \mathrm{~s}$ PCASP aerosol concentration immediately before (ascent profiles) or after (descent profiles) the aircraft profile occurrence, and correlated them with the in-cloud profiles averaged $N_{\mathrm{d}}$. In addition, samples with precipitating LWP (from the two dimensional cloud probe) higher than $5 \mathrm{~g} \mathrm{~m}^{-2}, \mathrm{LWP}<10 \mathrm{~g} \mathrm{~m}^{-2}$, and $N_{\mathrm{d}}$ $<10 \mathrm{~cm}^{-3}$ were discarded from the analysis. This was done to exclude drizzling and potentially broken clouds that might mask the aerosol indirect effect. $\mathrm{ACI}_{N}$ for a total of 70 samples collected during fourteen research flights was 0.76 , with a linear correlation of 0.81 (Fig. 13, gray circles), or an equivalent $\mathrm{ACI} \tau$ value of $0.25\left(\mathrm{ACI}_{N} / 3\right)$. In contrast, $\mathrm{ACI}_{N}$ (ACI $\tau)$ increased to $0.92(\sim 0.31)$ when this was estimated from 28 profiles performed during the four research flights analyzed in this study. A higher $\mathrm{ACI}_{\mathrm{N}}$ for this subset is consistent with higher cloud adiabaticity, more coupled conditions, and less precipitation than nighttime C-130 flights. This in situ $\mathrm{ACI}_{N}$ was within the range of the remote-sensing $\mathrm{ACI} \tau$ (average of 0.32) and supported the idea of a large ACI occurrence for this marine stratocumulus cloud regime. Our results differ from those in Terai et al. (2012), who reported an in situ $\mathrm{ACI}_{N}$ of 0.55 . This discrepancy may be because Terai et al. (2012) relied on a larger dataset with 

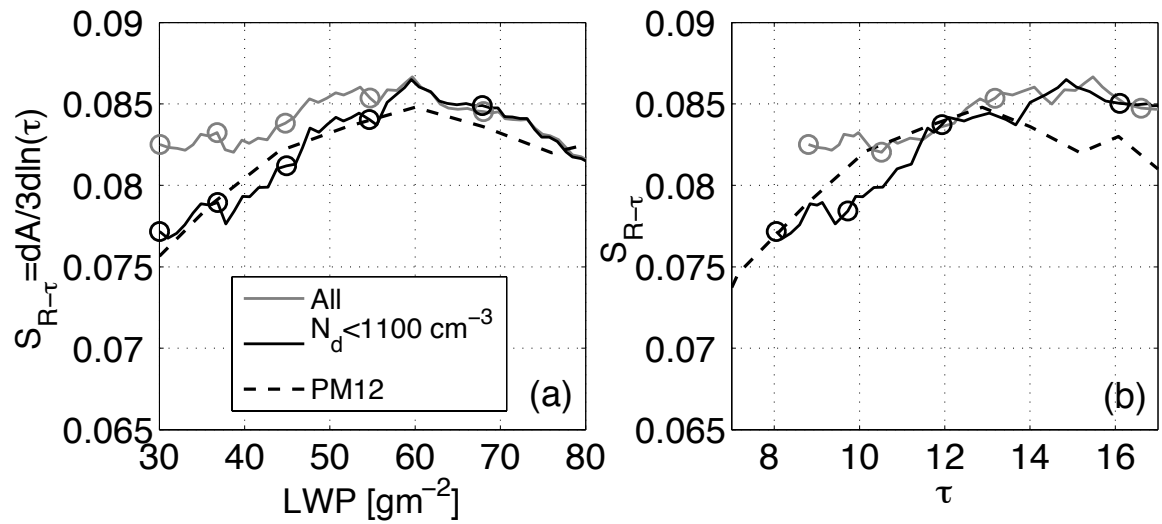

Fig. 14. Albedo relative susceptibility as a function of (a) LWP and (b) $\tau$ (binned as a function of LWP). Gray and black lines correspond to calculation made with all the data, and $N_{\mathrm{d}}<1100 \mathrm{~cm}^{-3}$, respectively. Black dashed lines (PM12) are relative susceptibilities reported in Painemal and Minnis (2012) over the Southeast Pacific near the coast. Circles indicate bins without overlapping.

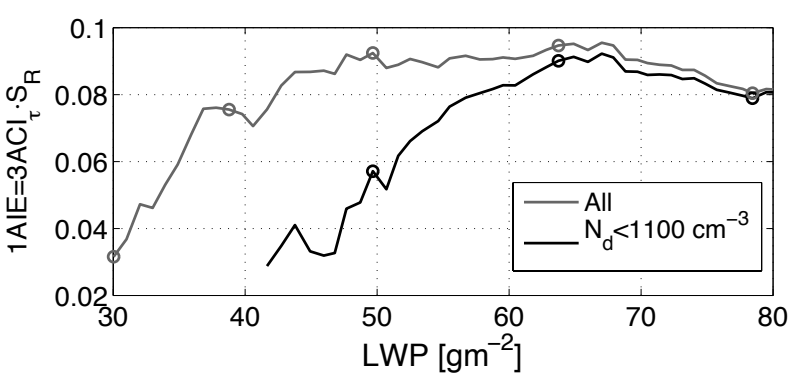

Fig. 15. The first aerosol indirect effect expressed as $1 \mathrm{AIE}=3$. $\mathrm{ACI}_{\tau} \cdot S_{R-\tau}$. Colors and symbols are defined in Figs. 12 and 14.

more offshore samples and included precipitating clouds. Moreover, their computation of $\mathrm{ACI}_{N}$ was obtained by maximizing the correlation between $N_{\mathrm{d}}$ and $N_{\mathrm{a}}^{\mathrm{ACI}_{N}}$. The estimate reported here is in better agreement with an independent aircraft-based study at $20^{\circ} \mathrm{S}$ and $72^{\circ} \mathrm{W}$ that reported $\mathrm{ACI}_{N}=0.71$ based on averaged data collected in similar coastal daytime conditions (Zheng et al., 2011). The high values of $\mathrm{ACI}_{N}$ reported here and in Zheng et al. (2011) for the more polluted coastal regions also support the similar conclusions from the WRF-Chem simulation study of Yang et al. (2012).

The higher ACI $\tau$ values obtained with higher $N_{\mathrm{d}}$ thresholds are consistent with expectations for scale aggregation developing within McComiskey and Feingold (2012). High, physically-unrealistic $N_{\mathrm{d}}$ were also more likely for more inhomogeneous clouds, for which the derived LWP variability is high but the derived optical depths remain radiatively smoothed and less variable. Thus, more stringent (lower) $N_{\mathrm{d}}$ values select for the more homogeneous scenes for which the $\mathrm{ACI} \tau$ values are more meaningful, despite the lower correlation.

\subsection{Albedo susceptibility and 1AIE}

The link between changes in cloud microphysics and actual changes in the albedo was investigated by means of the albedo relative susceptibility metric $\left(S_{R-\tau}\right)$. Albedo $A$ was derived from Streamer plane-parallel 8-stream radiative simulations at the top of the atmosphere by using $r_{\mathrm{e}}$ and $\tau$ obtained from the iterative method in Sect. 2.3. The high correlation between $\ln (\tau)$ and $A(r>0.8)$ simplified the $\ln (\tau)$ A slope calculation (Painemal and Minnis, 2012). Because the relative susceptibility calculation is sensitive to the solar zenith angle, we limited our analysis to samples with solar zenith angle within $15^{\circ}-35^{\circ}$, an interval that allowed us to reduce $S_{R}$ 's range of variability (Platnick and Oreopoulos 2008). The solar zenith angle range selected was also in agreement with MODIS Terra pass over the region (e.g. Painemal and Minnis, 2012).

Similar to ACI $\tau$, we computed $S_{R-\tau}$ for each LWP bin, using the same screening as in Sect. 2.4. $S_{R-\tau}$ typically increases with LWP and $\tau$, reaching a maximum $S_{R-\tau}$ of 0.086 for LWP of $60 \mathrm{~g} \mathrm{~m}^{-2}$ and $\tau$ of 14-15, and decreases thereafter (Fig. 14). $S_{R-\tau}$ was relatively insensitive to the $N_{\mathrm{d}}$ threshold for LWP $>60 \mathrm{~g} \mathrm{~m}^{-2}$, with a minimum of 0.082 for LWP $(\tau)$ of 80 (18). This result was consistent with satellite estimations obtained by combining Cloud and the Earth's Radiant Energy System (CERES) albedo and Moderate Resolution Imaging Spectroradiometer (MODIS) cloud observations aboard Terra (10:30 local time pass), and over the same study region. Satellite estimates yielded $S_{R}=0.083$, for LWP $(\tau)$ of $60 \mathrm{~g} \mathrm{~m}^{-2}$ (13-14) for coastal clouds (Painemal and Minnis, 2012). (Fig. 14, black dashed line). Both satellite and VOCALS susceptibilities are also in qualitative agreement with the simplified susceptibility approximation first put forth by Platnick and Twomey (1994) of $S_{0}=\frac{A(1-A)}{3 N_{\mathrm{d}}}$, equivalent to $S_{R}$ of $S_{R 0}=\frac{A(1-A)}{3}$, which increases with $\tau$ until reaching a $S_{R}$ maximum for $\tau$ of 13.33 . 
In addition, we found a better agreement between satellite and in situ $S_{R-\tau}$ for $N_{\mathrm{d}}<1100 \mathrm{~cm}^{-3}$ (Fig. 14, black solid lines), whereas the results were unaffected for LWP larger than $60 \mathrm{~g} \mathrm{~m}^{-2}$, in agreement with $\mathrm{ACI} \tau$, as it was discussed previously.

We note that while $S_{R-\tau}$ and ACI $\tau$ show different functional dependences on LWP, the maximum $S_{R-\tau}$ co-occurs with a maximum $\operatorname{ACI} \tau$. This emphasizes the radiative importance of LWP when evaluating the first aerosol indirect effect. We next calculated $1 \mathrm{AIE}$ as $3 \cdot \mathrm{ACI}_{\tau} \cdot S_{R-\tau} \cdot 1 \mathrm{AIE}$, depicted in Fig. 15, has low values for low LWP, mainly due to the influence of $S_{R-\tau}$. Similarly, large $S_{R-\tau}$ for LWP around $55-70 \mathrm{~g} \mathrm{~m}^{-2}$, produced a 1AIE maximum at $0.09-0.095$, or equivalent to an absolute change in albedo of 0.009-0.0095 if $N_{\mathrm{a}}$ increased in $10 \%$.

A simple calculation can help to put in context the quantities derived in our study. If one assumes a typical daily mean incoming solar radiation at the top of the atmosphere of $400 \mathrm{~W} \mathrm{~m}^{-2}$ (Petty, 2006), then a modest $10 \%$ increase in $N_{\mathrm{a}}$ for LWP of $65 \mathrm{~g} \mathrm{~m}^{-2}$ would produce a radiative forcing of approximately -3.6 to $-3.8 \mathrm{~W} \mathrm{~m}^{-2}$. These magnitudes are larger than the range derived from general circulation models ( -1.8 to $-0.3 \mathrm{Wm}^{-2}$, Quaas et al., 2009) but less than that reported using a WRF-Chem simulation focused on the SEP region (Yang et al., 2012). The radiative forcing estimate is specific to this region and provides a test for climate model AIE estimates for southeast Pacific stratocumulus.

\section{Summary and conclusion}

In this study, we combined remote sensing techniques to investigate the microphysical and radiative aspects of the first aerosol indirect effect. A strength of this study was the imposition of LWP constraints, the collocated aerosol-cloud property measurements (aerosol number concentration, cloud optical depth and liquid water path), and the ability to sample within a consistent meteorological regime. The reliance on airborne remotely-sensed variables increased the dataset size beyond that of the aircraft vertical profiles to near 4000 samples, equivalent to a spatial distance of over $400 \mathrm{~km}$. The LWP retrieval technique -based on a millimeter wave passive radiometer- was documented in Zuidema et al. (2012), while here we developed a physical algorithm to produce $\tau$ from broadband shortwave irradiances collected by an Eppley Precision Spectral Pyranometer. Although similar algorithms, based on pyranometer observations, have been utilized in the past, to our knowledge this is the first time that $\tau$ has been retrieved from an airborne pyranometer. We assessed a typical uncertainty in $\tau$ of near $10 \%$, mostly attributed the instrument calibration errors. The remote sensed $\tau$-LWP relationship was consistent with the one derived from the in situ cloud probes, but with a much larger spread. This was further supported by a comparison between the parameterized $N_{\mathrm{d}}$ (a function of $\tau$ and LWP) and the cloud probe
$N_{\mathrm{d}}$, showing similar mode values but with a tail of high, physically-unrealistic remotely-derived $N_{\mathrm{d}}$ values.

We calculated ACI $\tau$ for different LWP intervals, to isolate the effect of the aerosols in the cloud microphysics from other dynamical factors. ACI $\tau$ increased with LWP for LWPs smaller than $45 \mathrm{~g} \mathrm{~m}^{-2}$, remaining constant thereafter at values close to the theoretical limit. This suggests that this cloud regime is highly responsive to changes in the aerosol concentration. $\mathrm{ACI} \tau$ values were also examined as a function of the $N_{\mathrm{d}}$ threshold. Data subsets subjected to less stringent (higher) $N_{\mathrm{d}}$ thresholds possessed higher $\mathrm{ACI} \tau$ values. $\mathrm{ACI} \tau$ values were also higher when LWP values were smoothed using a 15 -s running mean. Both increases in $\mathrm{ACI} \tau$ values can be understood as scale aggregation impacts (McComiskey and Feingold, 2012). The smoothing reduces the variance within the dataset, increasing the correlation between cloud optical depth-aerosol pairs.

This study's mean ACI value of 0.32 (irrespective of $N_{\mathrm{d}}$ ) slightly exceeds other in situ aircraft observations in marine stratocumulus that did not stratify for LWP (0.11-0.27, Table 1 in McComiskey and Feingold, 2008). A similar analysis using surface-based remotely-sensed variables at Pt. Reyes finds slightly smaller ACI values of $0.18-0.22$ for the same range of LWPs compared to our estimates. We hypothesize that the higher ACI values for the southeast Pacific stratocumulus reflect the clouds high adiabaticity (Zuidema et al., 2012), for which the first aerosol indirect effect is optimized (Kim et al., 2008), as well as a more pristine marine background environment, in which additional accumulationmode aerosol is more easily activated than the land-based Pt. Reyes environment.

The albedo relative susceptibility $S_{R-\tau}$ was utilized to study the link between cloud microphysics and radiative response. The analysis indicated that clouds tended to be most susceptible to changes in their albedo for a LWP of $60 \mathrm{~g} \mathrm{~m}^{-2}$ and $\tau$ of 14 , and decreased thereafter. This tendency, especially for $S_{R-\tau}$ and LWP, was in agreement with satellite estimates from MODIS and CERES (Painemal and Minnis, 2012). This is an important result because it demonstrates that despite the coarser spatial resolution and potential retrieval artifacts, satellite observations provide a suitable dataset for estimating the cloud susceptibility in the Southeast Pacific regime. The dissimilar variation in $\mathrm{ACI} \tau$ and $S_{R-\tau}$ produced a net first aerosol indirect effect that is a minimum for LWP of 30-40 $\mathrm{g} \mathrm{m}^{-2}$, and a maximum for LWP at $68 \mathrm{~g} \mathrm{~m}^{-2}$ (relatively insensitive to $N_{\mathrm{d}}$ ), with a modest decrease for larger LWP. These results overall provide further insight and detail on a cloud region, the Southeast Pacific stratocumulus deck, that has the highest cloud radiative response per unit of aerosol perturbation of anywhere on the globe (Oreopoulos and Platnick, 2008; Painemal and Minnis, 2012). These 1AIE estimates exceed the global-range values reported for large-scale climate models (Quaas et al., 2009), but support similar findings from a WRF-Chem simulation by Yang et al. (2012). 
This study integrated available datasets on simultaneously-retrieved cloud properties towards what we believe is a new application. While the technique is promising in that much more of the cloud volume can be sampled, the technique also requires highly-accurate radiometric measurements and would benefit from using radiances rather than irradiances. We stress the need for more of such measurements if we are to understand and quantify aerosol indirect effects for the remote marine environment. In such environments, clouds are more easily susceptible to modification by aerosol, supporting the renewed interest in their geo-engineering.

Acknowledgements. D. Painemal and P. Zuidema were supported by NSF Large-Scale Dynamics Award 0745470 and NSF AGS Award 1233874 (PZ). D. Painemal was also supported by the NASA Postdoctoral Program at the NASA Langley Research Center. The authors are indebted to the staff and instrument scientists of the Research Aviation Facility and the National Center for Atmospheric Research that were involved in the aircraft C-130 operation. Wyoming Cloud Radar and Lidar datasets were provided by David Leon. Relevant comments from Graham Feingold as a member of D. Painemal's $\mathrm{PhD}$ thesis committee are gratefully acknowledged. We also thank Walter Robinson, Robert Wood, Christopher Bretherton, and Roberto Mechoso for their leadership of VOCALS-Rex, making this study possible. The comments and suggestions made by two anonymous reviewers are also acknowledged.

Edited by: R. Wood

\section{References}

Allen, G., Coe, H., Clarke, A., Bretherton, C., Wood, R., Abel, S. J., Barrett, P., Brown, P., George, R., Freitag, S., McNaughton, C., Howell, S., Shank, L., Kapustin, V., Brekhovskikh, V., Kleinman, L., Lee, Y.-N., Springston, S., Toniazzo, T., Krejci, R., Fochesatto, J., Shaw, G., Krecl, P., Brooks, B., McMeeking, G., Bower, K. N., Williams, P. I., Crosier, J., Crawford, I., Connolly, P., Allan, J. D., Covert, D., Bandy, A. R., Russell, L. M., Trembath, J., Bart, M., McQuaid, J. B., Wang, J., and Chand, D.: South East Pacific atmospheric composition and variability sampled along $20^{\circ} \mathrm{S}$ during VOCALS-REx, Atmos. Chem. Phys., 11, 5237-5262, doi:10.5194/acp-11-5237-2011, 2011.

Bennartz, R.: Global assessment of marine boundary layer cloud droplet number concentration from satellite, J. Geophys. Res., 112, D02201, doi:10.1029/2006JD007547, 2007.

Brenguier, J.-L., Pawlowska, H., Schüller, L., Preusker, R., Fischer, J., and Fouquart, I.: Radiative Properties of Boundary Layer Clouds: Droplet Effective Radius versus Number Concentration, J. Atmos. Sci., 57, 803-821, 2000.

Bretherton, C. S., Wood, R., George, R. C., Leon, D., Allen, G., and Zheng, X.: Southeast Pacific stratocumulus clouds, precipitation and boundary layer structure sampled along $20^{\circ} \mathrm{S}$ during VOCALS-REx, Atmos. Chem. Phys., 10, 10639-10654, doi:10.5194/acp-10-10639-2010, 2010.
Bush, B. C., Valero, F. P. J., Simpson, A. S., and Bignone, L.: Characterization of Thermal Effects in Pyranometers: A Data Correction Algorithm for Improved Measurement of Surface Insolation, J. Atmos. Oceanic Technol., 17, 165-175, 2000.

Cahalan, R. F., Ridgeway, W., Wiscombe, W., Bell, T., and Snider, J. B.: The albedo of fractal stratocumulus clouds, J. Atmos. Sci., 51, 2434-2455, 1994.

Comstock, K. K., Wood, R., Yuter, S. E., and Bretherton, C. S.: Reflectivity and rain rate in and below drizzling stratocumulus, Q. J. Roy. Meteor. Soc., 130, 2891-2918, doi:10.1256/qj.03.187, 2004.

Di Girolamo, L., Liang, L., and Platnick S.: A global view of one-dimensional solar radiative transfer through oceanic water clouds, Geophys. Res. Lett., 37, L18809, doi:10.1029/2010GL044094, 2010.

Feingold, G.: Modeling of the first indirect effect: Analysis of measurement requirements, Geophys. Res. Lett., 30, 1997, doi:10.1029/2003GL017967, 2003.

Feingold, G., Remer, L. A., Ramaprasad, J., Kaufman, Y. J.: Analysis of smoke impact on clouds in Brazilian biomass burning regions: An extension of Twomey's approach, J. Geophys. Res., 106, 907-22,922, 2001.

Hu, Y. X. and Stamnes, K.: An accurate parameterization of the radiative properties of water clouds suitable for use in climate models, J. Climate, 6, 728-742, 1993.

Jones, C. R., Bretherton, C. S., and Leon, D.: Coupled vs. decoupled boundary layers in VOCALS-REx, Atmos. Chem. Phys., 11, 7143-7153, doi:10.5194/acp-11-7143-2011, 2011.

Kato, S. and Marshak, A.: Solar zenith and viewing geometrydependent errors in satellite retrieved cloud optical thickness: Marine stratocumulus case, J. Geophys. Res., 114, D01202, doi:10.1029/ 2008JD010579, 2009.

Kato, S., Ackerman, T. P., Clothiaux, E. E., Mather, J. H., Mace, G. G., Wesely, M. L., Murcray, F., and Michalsky J.: Uncertainties in modeled and measured clear-sky surface shortwave irradiances, J. Geophys. Res., 102, 25881-25898, doi:10.1029/97JD01841, 1997.

Key, J. and Schweiger, A. J.: Tools for atmospheric radiative transfer: Streamer and FluxNet, Comput. Geosci., 24, 443-451, 1998.

Leontyeva, E. and Stamnes, K.: Estimations of cloud optical thickness from ground-based measurements of incoming solar radiation in the Arctic, J. Climate, 7, 566-578, 1994.

Kim, B.-G., Miller, M. A., Schwartz, S. E., Liu, Y., and Min, Q.: The role of adiabaticity in the aerosol first indirect effect, J. Geophys. Res., 113, D05210, doi:10.1029/2007JD008961, 2008.

McComiskey, A., and Feingold, G.: Quantifying error in the radiative forcing of the first aerosol indirect effect, Geophys. Res. Lett., 35, L02810, doi:10.1029/2007GL032667, 2008.

McComiskey, A. and Feingold, G.: The scale problem in quantifying aerosol indirect effects, Atmos. Chem. Phys., 12, 1031-1049, doi:10.5194/acp-12-1031-2012, 2012.

McComiskey, A., Feingold, G., Frisch, A. S., Turner, D. D., Miller, M. A., Chiu, J. C., Min, Q., and Ogren, J. A.: An assessment of aerosol-cloud interactions in marine stratus clouds based on surface remote sensing, J. Geophys. Res., 114, D09203, doi:10.1029/2008JD011006, 2009.

Muñoz, R. C. and Garreaud, R.: Dynamics of the Low-Level Jet off the West Coast of Subtropical South America, Mon. Wea. Rev., 133, 3661-3677, doi:http://dx.doi.org/10.1175/MWR3074.1, 
2005.

Oreopoulos, L., and Platnick, S.: The radiative susceptibility of cloudy atmospheres to droplet number perturbations: 2. Global analysis from MODIS, J. Geophys. Res. , 113, doi:10.1029/2007JD009655, 2008.

Painemal, D. and Minnis, P.: On the dependence of albedo on cloud microphysics over marine stratocumulus clouds regimes determined from CERES data, J. Geophys. Res., 117, D06203, doi:10.1029/2011JD017120, 2012.

Painemal, D. and Zuidema, P.: Microphysical variability in southeast Pacific Stratocumulus clouds: synoptic conditions and radiative response, Atmos. Chem. Phys., 10, 6255-6269, doi:10.5194/acp-10-6255-2010, 2010.

Painemal, D. and Zuidema, P.: Assessment of MODIS cloud effective radius and optical thickness retrievals over the Southeast Pacific with VOCALS-Rex in situ measurements, J. Geophys. Res., 116, D24206, doi:10.1029/2011JD016155, 2011.

Pazmany, A.: A compact $183 \mathrm{GHz}$ radiometer for airborne and ground-based water vapor and liquid water sensing, IEEE Trans. Geosci. Rem. Sens., 45, 2202-2206, 2007.

Petty, G. W. (ed.): A first course in atmospheric radiation, 444 pp., Sundog, Madison, Wis., 2006.

Pinto, J., Curry, J., and Fairall, C.: Radiative characteristics of the Arctic atmosphere during spring as inferred from ground-based measurements, J. Geophys. Res., 102, 6941-6952, 1997.

Platnick, S. and Twomey, S.: Determining the susceptibility of cloud albedo to changes in droplet concentration with the Advanced Very High Resolution Radiometer, J. Appl. Meteorol., 33, 334-347, 1994.

Platnick, S. and Oreopoulos, L.: Radiative susceptibility of cloudy atmospheres to droplet number perturbations: 1. Theoretical analysis and examples from MODIS, J. Geophys. Res., 113, D14S20, doi:10.1029/2007JD009654, 2008.

Ricchiazzi, P., Yang, S., Gautier, S. and Sowle, D.: SBDART: A research and teaching software tool for plane-parallel radiative transfer in the earth's atmosphere, Bull. Amer. Meteor. Soc., 79, 2101-2114, 1998.

Quaas, J., Ming, Y., Menon, S., Takemura, T., Wang, M., Penner, J. E., Gettelman, A., Lohmann, U., Bellouin, N., Boucher, O., Sayer, A. M., Thomas, G. E., McComiskey, A., Feingold, G., Hoose, C., Kristjánsson, J. E., Liu, X., Balkanski, Y., Donner, L. J., Ginoux, P. A., Stier, P., Grandey, B., Feichter, J., Sednev, I., Bauer, S. E., Koch, D., Grainger, R. G., Kirkevåg, A., Iversen, T., Seland, Ø., Easter, R., Ghan, S. J., Rasch, P. J., Morrison, H., Lamarque, J.-F., Iacono, M. J., Kinne, S., and Schulz, M.: Aerosol indirect effects - general circulation model intercomparison and evaluation with satellite data, Atmos. Chem. Phys., 9, 8697-8717, doi:10.5194/acp-98697-2009, 2009.

Street, J. O., Carroll, R. J., and Ruppert, D.: A note on computing robust regression estimates via iteratively reweighted least squares, Am. Stat., 42, 152-154, doi:10.2307/2684491, 1988.
Twohy, C. H., Petters, M. D., Snider, J. R., Stevens, B., Tahnk, W., Wetzel, M., Russell, L., and Burnet, F.: Evaluation of the aerosol indirect effect in marine stratocumulus clouds: Droplet number, size, liquid water path, and radiative impact, J. Geophys. Res., 110, D08203, doi:10.1029/2004JD005116, 2005.

Twomey, S.: The influence of pollution on the short wave albedo of clouds, J. Atmos. Sci., 34, 1149-1152, 1977.

Wood, R., Mechoso, C. R., Bretherton, C. S., Weller, R. A., Huebert, B., Straneo, F., Albrecht, B. A., Coe, H., Allen, G., Vaughan, G., Daum, P., Fairall, C., Chand, D., Gallardo Klenner, L., Garreaud, R., Grados, C., Covert, D. S., Bates, T. S., Krejci, R., Russell, L. M., de Szoeke, S., Brewer, A., Yuter, S. E., Springston, S. R., Chaigneau, A., Toniazzo, T., Minnis, P., Palikonda, R., Abel, S. J., Brown, W. O. J., Williams, S., Fochesatto, J., Brioude, J., and Bower, K. N.: The VAMOS Ocean-Cloud-Atmosphere-Land Study Regional Experiment (VOCALS-REx): goals, platforms, and field operations, Atmos. Chem. Phys., 11, 627-654, doi:10.5194/acp-11-627-2011, 2011.

Yang, Q., Gustafson Jr., W. I., Fast, J. D., Wang, H., Easter, R. C., Wang, M., Ghan, S. J., Berg, L. K., Leung, L. R., and Morrison, H.: Impact of natural and anthropogenic aerosols on stratocumulus and precipitation in the Southeast Pacific: a regional modelling study using WRF-Chem, Atmos. Chem. Phys., 12, 8777-8796, doi:10.5194/acp-12-8777-2012, 2012.

Zhang, Z. and Platnick, S: An assessment of differences between cloud effective particle radius retrievals for marine water clouds from three MODIS spectral bands, J. Geophys. Res., 116, D20215, doi:10.1029/2011JD016216, 2011.

Zheng, X., Albrecht, B., Jonsson, H. H., Khelif, D., Feingold, G., Minnis, P., Ayers, K., Chuang, P., Donaher, S., Rossiter, D., Ghate, V., Ruiz-Plancarte, J., and Sun-Mack, S.: Observations of the boundary layer, cloud, and aerosol variability in the southeast Pacific near-coastal marine stratocumulus during VOCALSREx, Atmos. Chem. Phys., 11, 9943-9959, doi:10.5194/acp-119943-2011, 2011.

Zuidema, P. and Evans, K. F.: On the Validity of the Independent Pixel Approximation for Boundary Layer Clouds Observed during ASTEX, J. Geophys. Res., 103, 6059-6074, 1998.

Zuidema, P., Leon, D., Pazmany, A., and Cadeddu, M.: Aircraft millimeter-wave passive sensing of cloud liquid water and water vapor during VOCALS-REx, Atmos. Chem. Phys., 12, 355-369, doi:10.5194/acp-12-355-2012, 2012.

Zuidema, P., Baker, P., Han, Y., Intrieri, J., Key, J., Lawson, P., Matrosov, S., Shupe, M., Stone, R., and Uttal, T.: An Arctic springtime mixed-phase cloudy boundary layer observed during SHEBA, J. Atmos. Sci., 62, 160-176, 2005. 